mendations featured in the college's latest report on diseases related to smoking. ${ }^{7}$ The foundation of Action against Alcohol Abuse was the outcome of a decision of the conference of royal colleges to put pressure on politicians to restrict access to alcohol. ${ }^{8}$

The current issue is how much the colleges should engage in the political debate on funding of the NHS. The argument against such participation is that the colleges have limited experience of political campaigning. Their strength is based on wide knowledge and experience and the thoroughness with which they tackle medical issues. Their weakness is that they are dealing with a government that has scant respect for academic or professional standards and is in a hurry to curtail what it sees as professional monopolistic practice. Whereas leaders of industry understand the political process - the need to cultivate political allies, the importance of timing, and awareness of where real power lies - the colleges have often avoided public approaches to politicians until a problem has become acute.

If, however, the colleges are to raise their political profile they should build on what they have done so well in the past: publish reports based on accurate information about hazards to health and changes in the health of the nation. It should be possible, for example, to gather information on the consequences to health of underfunding through the network of college members and to initiate medical audit to show whether excess morbidity is related to delay or deficiencies in providing care.

If the colleges choose to follow this path their officers cannot behave like union general secretaries in the public sector. Sir Raymond Hoffenberg, president of the Royal College of Physicians, and Mr Rodney Bickerstaffe, secretary of the National Union of Public Employees, are no doubt equally concerned about the future of the NHS; but they would be unlikely to express their concern in the same way. Now that the NHS is a matter of political dispute rather than consensus the colleges are justified in spelling out the likely consequences for standards of care in an underfunded, fragmented health service.

Postgraduate Dean,

ELIZABETH SHORE

North West Thames Regional Health Authority,

British Postgraduate Medical Federation,

London WCIN 3EJ

1 Timmins N. Doctors win concession on extra health cash. Independent $1988 \mathrm{Jan} 14: 2$ ( $\mathrm{col} 1$ ).

2 Grey-Turner E, Sutherland FM. History of the British Medical Association. Vol II 1932-1981. London: British Medical Association, 1982.

3 Honorary Secretary of the Conference of Medical Royal Colleges and their Faculties in the United Kingdom. Diagnosis of brain death. BrMed f 1976;ii:1187-8.

4 Royal College of Psychiatrists. Alcohol and alcoholism: report of a special committee of the Royal College of Psychiatrists. London: Tavistock, 1979.

5 Howie J. Threat to the PHLS. Br Med f 1985;290:579-80.

6 Royal College of Physicians. Smoking and health. London: Pitman Medical, 1962.

7 Royal College of Physicians. Health or smoking. Follow-up (4th) report of the Royal College of Physicians. London: Pitman Publishing, 1983.

8 Anonymous. Action on alcohol abuse is born [Editorial]. Br Med f 1983;287:779-80.

\section{Slowing the speedy}

\section{Strong evidence that speed limits reduce deaths}

The Association of Chief Police Officers recently announced guidelines for motorway speeding: a fixed fine of $£ 20$ for those driving at speeds of $85-94$ miles/hour $(136-150 \mathrm{~km} / \mathrm{hour})$ and that prosecution should be considered only for speeds above $95 \mathrm{miles} /$ hour $(152 \mathrm{~km} /$ hour$)$. The legal limit on motorways is $70 \mathrm{miles} /$ hour $(112 \mathrm{~km} /$ hour$)$. After reaction to these proposals the police hastened to add that these were only guidelines and that an officer could prosecute anybody travelling at over $70 \mathrm{miles} /$ hour $(112 \mathrm{~km} / \mathrm{hour})$. Any suggestion that speed limits should be relaxed should be resisted on public health grounds because the evidence is so strong that the limits prevent deaths and serious injuries.

The association's proposals are set against a background of speeding having become increasingly common: in the 1983 survey two fifths of vehicles exceeded the statutory limit. ${ }^{1}$ It is true that deaths on the roads have fallen - for example, from 6614 in 1977 to 5382 in 1986 - but the fall would probably have been greater if speed limits had been enforced more vigorously. There is no cause for complacency because road traffic accidents are the leading cause of premature death ${ }^{2}$ and of serious injuries -69000 in 1986.

The epidemiological study of road traffic accidents has been fruitful: more is known about the characteristics associated with accidents and the causes of accidents than about many of the leading "natural" causes of death. The underlying cause is speed. The laws of physics tell us that collisions may occur only when two objects have velocity relative to each other and that the damage that results from a collision is dictated by kinetic energy, which is proportional to mass and the square of the velocity. Many other characteristics - the age of the driver, the condition of the vehicle and the road, alcohol, drugs, personality type, and physical handicap-may be associated with accidents, but relative velocity is the cause. The fatality of accidents is directly related to speed limits. ${ }^{1}$

To control accidents it is thus necessary to control relative velocity. Much has been achieved with improved vehicle design, road layouts, lighting, and signposting and by legislation, including speed restrictions, yearly tests of roadworthiness, mandatory wearing of seat belts, and breath tests for alcohol. The introduction of speed limits resulted in appreciable reductions in deaths and serious injuries from road traffic accidents in many countries: in Britain, introducing a speed limit of 30 miles/hour ( $48 \mathrm{~km} / \mathrm{hour})$ in $1935 \mathrm{led}$ to a $15 \%$ reduction in deaths and serious injuries; in Switzerland a limit of $50 \mathrm{~km} /$ hour was introduced in towns in 1959 and caused a $21 \%$ fall, whereas a similar limit in Germany caused a $30 \%$ fall. $^{3}$ When a limit of 40 miles/hour $(64 \mathrm{~km} /$ hour) was introduced in out of town areas in Britain there was a $30 \%$ fall in deaths and serious injuries and a similar limit of

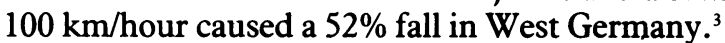

Clearly there is an economic balance to be achieved between speed (journey time saved) and the risk of death or injury (years of life lost or impaired). The current estimates of the costs of road traffic accidents are $£ 300000$ for a death and $£ 18000$ for a serious injury. When considering the balance of costs and benefits, however, it is important to realise that those killed and injured on the roads are not only those who drive too fast. ${ }^{4}$ In 1986,2111 road deaths were of pedestrians or cyclists, and mortality among those groups is not falling as fast as that among drivers. ${ }^{1}$ Indeed, when wearing seat belts became mandatory for drivers and passengers in the front seat deaths and serious injuries among passengers in the back seats (most of whom were unbelted) and pedestrians and cyclists actually increased. ${ }^{5}$ Most pedestrians are children and the 
elderly ${ }^{6}$ and may be the innocent victims of the lust for speed of some drivers.

Those who make policy must understand that any decision to relax the enforcement of laws on speeding is to condemn some of our citizens to death. ${ }^{7}$ The present publicity is about speeding on motorways, but a speed of above 90 miles/hour (144 km/hour) on motorways often converts to 50 miles/hour $(80 \mathrm{~km} /$ hour$)$ or above on urban thoroughfares, which include shopping streets, and to $40 \mathrm{miles} / \mathrm{hour}$ ( $64 \mathrm{~km} /$ hour) or above on residential streets, which include children's play areas. Though no speed is safe, a safer speed is a lower speed. Legislation to control speed is in the interest of both individual people and the community to reduce deaths, injuries, and damage to property and the costs of these losses. Enforcing speed limits is not particularly difficult: the technology, capable of photographing a vehicle (even in fog) and superimposing its speed, date, and location, has existed for over a decade. ${ }^{1}$

ROBERT WEST

Senior Lecturer,

Department of Epidemiology and Community Medicine,

University of Wales College of Medicine,

Cardiff CF4 4XN

1 Department of Transport. Road accidents for years 1972-86. London: HMSO, 1973-87.

2 Office of Population Censuses and Surveys. Mortality statistics in England and Wales 1974-85. London: HMSO, 1975-87.

3 Road research laboratory. Research on road safety. London: HMSO, 1963.

4 Whitlock FA. Death on the road: study in social violence. London: Tavistock, 1971.

5 Harvey AC, Durbin J. Effect of seat belt legislation on British road casualties. Fournal of the Royal Statistical Society 1986;149:187-210.

National Consumer Council. What is wrong with walking? London: HMSO, 1987.

7 Foege WH. Highway violence and public policy. $N$ Engl f Med 1986;316:1407-8.

\title{
The longitudinal study and the social distribution of cancer
}

\author{
The study will produce vital information
}

Prospective studies in which many subjects are followed over many years to determine their pattern of mortality and incidence of cancer are major undertakings. The Office of Population Censuses and Surveys helps health workers enormously by identifying relevant events among subjects in such studies through the National Health Service central register. In 1971 the office started a prospective study, the longitudinal study, of about $1 \%$ of the population of the 1971 census-over 570000 people. This made it the largest prospective study in Britain and comparable in size with the large studies of mortality by the American Cancer Society (about one million people) and the National Institutes of Health (about 250000 military veterans). The relation of the demographic and social factors covered by the census to disease may thus be studied in a representative sample of the whole population.

The longitudinal study is an ambitious study that adds an extra dimension to the statistical information provided by the Registrar General. Only the Office of Population Censuses and Surveys could have carried out the study as it is guardian of the census and could perform the whole enterprise inhouse, thereby preserving the confidentiality of the census. The latest publication ${ }^{1}$ from the study is the first on the incidence of cancer, and it complements an earlier report on mortality. ${ }^{2}$ It contains a wealth of detail not only on social factors but also on marital state, parity, and age at first birth, with more than 100 tables as well as 25 figures.

The importance of socioeconomic factors in the causation of cancer is well known. Little is known, however, about how socioeconomic factors increase cancer, apart from smoking, which explains the higher incidence of lung cancer in those who are poorer. Much of the information on socioeconomic factors and cancer has come from cross sectional surveys in which the social and occupational details are collected after the event, which obviously allows scope for bias. Indeed, the quality of the occupational data on death certificates for many retired people is such that the Registrar General restricts the main analyses on this subject to people aged under 65 . The longitudinal study, however, allows mortality and the incidence of cancer to be studied in relation to social factors even when the relevant events occur well past the usual retirement age.
The longitudinal study is probably also unique in using five variables from the census that are relevant to the social distribution of cancer-namely, housing tenure, access to household amenities, access to cars, educational qualifications, and social class. These are, of course, interrelated, but they must all be examined if every attempt is to be made to understand the nature of social influences on the causes of cancer. The present study confirms the validity of the Registrar General's broad social class groupings. It finds for example, that whichever of the five measures is used the incidences of cancers of the stomach, lung, and cervix are highest in those in the lowest socioeconomic groups, whereas the reverse (although less pronounced) is the case for cancers of the breast and ovary.

The report also indicates something of what the longitudinal study could produce in the future. The accuracy and reliability of the national scheme of cancer registration is becoming more important with the increasing interest, among both the public and scientists, in cancer in small areas, such as near Sellafield and Dounreay. The longitudinal study has the potential to validate certain aspects of this scheme. Furthermore, it may examine not only cancer survival in relation to social and other factors but also the prevalence of cancer.

The study deals, however, only with the time from 1971 to 1975 , presumably because this was the only quinquennium for which cancer registrations for the whole country were regarded as fairly complete when the analysis was started. Mention is made that a large number of recent registrations have now been linked to the cohort and are awaiting analysis. We must hope that resources may be found to continue to exploit this study, which is perhaps the largest cohort study of the incidence of cancer in the world. It promises to be a fruitful source of information for years to come.

Director,

L J KINLEN

Cancer Research Campaign,

Cancer Epidemiology Unit,

University of Edinburgh,

Edinburgh EH8 9JZ

\footnotetext{
1 Leon DA. Longitudinal study: social distribution of cancer. London: HMSO, 1988. (Series LS No 3

OPCS.)
Fox AJ, Goldblatt PO. Longitudinal study: sociodemographic mortality differentials. London: HMSO, 1982. (Series LS No 1 OPCS.)
} 